\title{
Learning Style and Behavior Analysis A Study on the Learning Management System Manhali
}

\author{
Ismail EL HADDIOUI \\ LIROSA lab, Abdelmalek Essaadi University \\ Faculty of Sciences, Tetouan, Morocco \\ B.P. 1939, Tetouan 93000, Morocco
}

\author{
Mohamed KHALDI \\ LIROSA lab, Abdelmalek Essaadi University \\ Faculty of Sciences, Tetouan, Morocco \\ B.P.2121, Mhanech II, Tetouan, Morocco
}

\begin{abstract}
This paper presents a study performed on the Learning Management System Manhali used to analyze and evaluate the learners' online behavior. This study is addressed to first year students in computer science to study their learning style from behavior data on the e-learning platform, or from other tools to measure learning style such as the ILS questionnaire of Felder and Silverman. The paper also introduces the main components of the learner profile of our e-learning system and the method that we created to evaluate and regroup learners according to their behavior on the platform.
\end{abstract}

\section{General Terms}

E-Learning; learning management system; online learning platform; virtual learning environment.

\section{Keywords}

Learner modeling; learner profile; learner behavior; learning style; behavioral analysis system.

\section{INTRODUCTION}

In e-learning, the teacher may lose the human interaction that exists a classic classroom with all the information that can be drawn from this as the estimation of differences in learning styles, approaches to learn and levels of intellectual development of students. In this case, the learner profile is considered as an essential element of a virtual learning environment to collect data required to adapt the educational content to the current needs of each learner. In our first paper, we introduced the analysis of learners' behavior on e-learning platforms and the data used for this study [1]. The second paper presented mainly the use of eye-tracking technology to track the interest and emotions of learners [2]. In this paper, we present the learner profile that achieved with our previous studies about e-learners modeling.

The learner profile includes several data such as personal information, learner machine information, his online behavior, domain competence and learning style. These data can be obtained by several methods, personal data are filled by asking the learner directly by a form on the platform, the learner machine information is found in the environment variables of the web server [1], the behavior is analyzed from the traces that learner leaves on the platform and also the statistics of using the pedagogical tools, domain competence can be found by comprehensive tests and learning style can be determined by a questionnaire [3].

The remaining of the paper is structured as follows: Section II. Learning Style, describes the models used to measure the style learning and compares two main models, model of kolb and model of Felder and Silverman. Section III. Learner Profile of Manhali System, shows the components of the learner profile on the learning management system Manhali that we have developed in our laboratory, and explains our approach to analyze the learning styles of learners from their behavior on the platform. The paper finishes with conclusions.

\section{LEARNING STYLE}

Learning style is one of the individual differences that play an important role in learning. Learning style designates everything that is characteristic to an individual when she/he is learning, i.e. a specific manner of approaching a learning task, the learning strategies activated in order to fulfill the task [4]. There have been given several definitions:

- A predisposition on the part of some students to adopt a particular learning strategy regardless of the specific demands of the learning task [5];

- The composite of characteristic cognitive, affective, and psychological factors that serve as relatively stable indicators of how a learner perceives, interacts with, and responds to the learning environment [6];

- An individual's preferred approach to organizing and presenting information [7];

- The way in which learners perceive, process, store and recall attempts of learning [8];

- Distinctive behaviors which serve as indicators of how a person learns from and adapts to his environment, and provide clues as to how a person's mind operates [9];

- A gestalt combining internal and external operations derived from the individual's neurobiology, personality and development, and reflected in learner behavior [10]

As we can see, learning style has been attributed several connotations in the literature. That is why there are many models in this research field [11]:

- Learning Styles Theory of Kolb (1985);

- Index of Learning Styles of Felder and Silverman (1988);

- Learning Styles of Honey and Mumford (1992);

- Student Learning Style Scales of Grasha (1996);

- Multiple Intelligences of Gardner (1999);

- Auditory Visual Tactile Learning Styles of Sarasin (1998).

In this study, we will compare two main models of measurement learning style, model of kolb and model of Felder and Silverman. 


\subsection{Kolb's Learning Styles}

Kolb identified based on the various modes of learning, four learning styles [12]:

\subsubsection{Accommodating Style (Active, Concrete)}

The learner asks the question: What happens if...? He learns primarily by "manipulation" and performing tasks. He likes to be involved in the planning and implementation of activities, he tends to solve problems through trial and error method rather than by logic and he tends to rely on the reflections of others rather than on his own analysis, he agrees to take risks.

\subsubsection{Diverging Style (Concrete, Reflective)}

The learner asks the question: Why? He has a keen sense of observation. He has the ability to perceive objects and problems from different angles, he excels in innovative activities such as brainstorming sessions, he has a fertile imagination and varied interests; he is interested in people and strongly attached to feelings.

\subsubsection{Assimilating Style (Reflective, Abstract)}

The learner asks the question: What? He has the ability to logically organize disparate information. He prefers to work on ideas and theories rather than practical applications.

\subsubsection{Converging Style (Abstract, Active)}

The learner asks the question: How? He has the ability to apply in practice the ideas and theories, solving problems and making decisions. However, he prefers solving problems that have a single solution. Finally, it is easier for him to perform technical tasks more than be involved in interpersonal or social controversies.

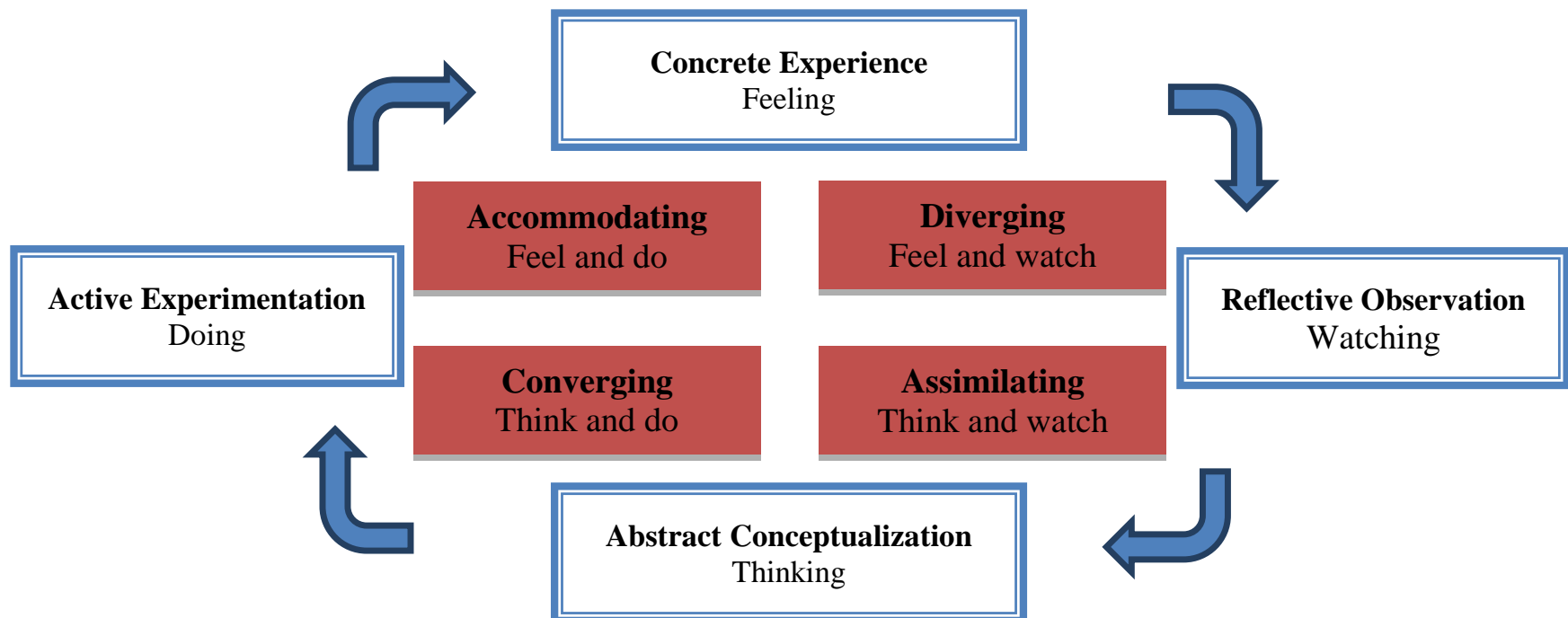

Figure 1. Kolb's learning styles

\subsection{Felder-Silverman Learning Styles}

Felder believes that all individual differences that include personal preferences for learning, educational activities, and also intellectual and psychological differences, refer to the learning style of an individual. For him, the learning style of a learner should be considered in terms of presentation, organization, processing and assimilation of information [11].

He proposes a model composed of four dimensions with the assumption that the student's learning style may be defined in part by the answers to four questions [13]:

1. How does the student prefer to process information: "actively" through engagement in physical activity or discussion, or "reflectively" through introspection?

2. What type of information does the student preferentially perceive: "sensory" sights, sounds, physical sensations, or "intuitive" memories, ideas, insights?

3. Through which modality is sensory information most effectively perceived: "visual" pictures, diagrams, graphs, demonstrations, or "verbal" sounds, written and spoken words and formulas?

4. How does the student progress toward understanding: "sequentially" in a logical progression of small incremental steps, or "globally" in large jumps, holistically?

Felder proposes the ILS questionnaire (Index of Learning Styles) composed of 44 closed questions with two answers (a and b) by forming 4 groups of 11 questions to evaluate the position of a student on a scale [14]. Each group of questions defines a dimension to the cognitive model of a student that is composed of four dimensions (D1, D2, D3 and D4). Each dimension ranges from -11 to 11 with the following degrees [11]:

- From 1 to 3: uncertain

- From 5 to 7: Moderate

- From 9 to 11: strong

(b)

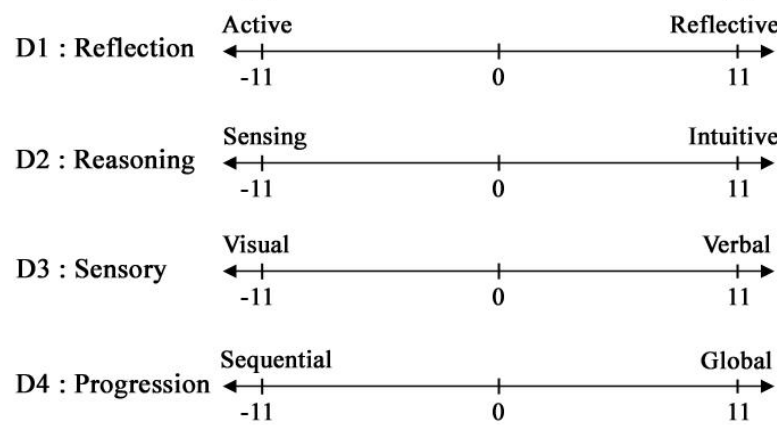

Figure 2. The four dimensions of the ILS questionnaire of Felder 
The first dimension D1 is the reflection, it varies from active to reflective. Active learners tend to retain and understand information best by doing something active with it, discussing or applying it or explaining it to others. Reflective learners prefer to think about it quietly first. Also, active learners tend to like group work more than reflective learners, who prefer working alone. Sitting through lectures without getting to do anything physical but take notes is hard for both learning types, but particularly hard for active learners.

The second dimension D2 is the reasoning, it varies from sensing to intuitive. Sensing learners tend to like learning facts, and intuitive learners often prefer discovering possibilities and relationships. Also, sensors often like solving problems by well-established methods and dislike complications and surprises; intuitors like innovation and dislike repetition. Sensors are more likely than intuitors to resent being tested on material that has not been explicitly covered in class. Sensors tend to be patient with details and good at memorizing facts and doing hands-on (laboratory) work; intuitors may be better at grasping new concepts and are often more comfortable than sensors with abstractions and mathematical formulations. Sensors also tend to be more practical and careful than intuitors; intuitors tend to work faster and to be more innovative than sensors. And finally, sensors don't like courses that have no apparent connection to the real world; intuitors don't like "plug-and-chug" courses that involve a lot of memorization and routine calculations.

The third dimension D3 is the sensory, it varies from visual to verbal. Visual learners remember best what they see, like pictures, diagrams, flow charts, time lines, films, and demonstrations. Verbal learners get more out of words, written and spoken explanations. Everyone learns more when information is presented both visually and verbally.

The last dimension D4 is the progression, it varies from sequential to global. Sequential learners tend to gain understanding in linear steps, with each step following logically from the previous one. Global learners tend to learn in large jumps, absorbing material almost randomly without seeing connections, and then suddenly "getting it". Also, sequential learners tend to follow logical stepwise paths in finding solutions; global learners may be able to solve complex problems quickly or put things together in novel ways once they have grasped the big picture, but they may have difficulty explaining how they did it [15].

\section{LEARNER PROFILE OF MANHALI SYSTEM}

The learner profile of Manhali LMS contains 5 types of basic information about the learner: personal information, learner machine information, domain competence, online behavior and learning style.

\subsection{Personal Information}

Name, gender, email, group / class, date of birth and date of registration are the most common learner's personal information in learning management systems (LMS). To choose the right learning strategy for a learner, there are two things to know, age and gender.

About age, a course presented to a teenager is different than the same content presented to a child or an adult. For this, the teacher must adapt his motivational tools according to the interests and needs of his audience.

Also, gender is very important to adapt the scientific content and to choose a pedagogical strategy. Studies of students show that boys and girls and men and women tend to differ in terms of intrinsic motivation, study strategies, and learning strategies. Females tend to prefer cooperation, note-taking, and task mastery, whereas men are more likely to prefer competition and independent work, and challenge, and avoid note-taking as a study strategy [16].

\subsection{Learner Machine Information}

This information is used to adjust the display of the platform according to the learner's machine configuration. The environment variable "HTTP_USER_AGENT" of a web server provides three types of information, the user's web browser, browser language and the operating system. This information can be used to resolve display problems, and to choose the best language for the user in multilingual platforms. We can also detect the screen resolution of the learner through a simple JavaScript code that measures the screen size in pixels.

\subsection{Domain Competence}

To estimate learner's competences, the platform Manhali contains two evaluation tools, assignments and quizzes. At the end of each chapter of the course, the teacher can add a quiz to test learner's competences, the system automatically manages the QCM by displaying the correct answers and the score obtained by the learner. Teachers can also add an assignment; learners must make their answers before the deadline, and then the teacher will give the scores that appear on learner profile.

\subsection{Learner's Behavior}

\subsubsection{Indicators and Behavior Score}

To analyze the behavior of learners, we chose seven key indicators:

- Total time spent on the platform;

- Number of connections to the platform;

- Number of visited pages;

- Number of tries in self-evaluation;

- Number of achieved homework assignments;

- Number of comments on course and article section;

- Number of messages.

For each indicator, we calculate the percentage of the number of activities performed by the learner on the total number of activities performed by all active learners of his class. An active learner is a learner who accessed at least one time to the platform.

For example, to calculate the score of the first indicator, we use the formula: Connection_score = Number_of_connections / Total_number_of_connections $* 100$

Where:

Number_of_connections is the number of connections of this learner;

Total_number_of_connections is the total number of connections of all active learners of his class.

To give a final behavior score for a learner, we calculate the average of the seven scores obtained by this learner. And then Manhali classifies learners on 5 grades (A, B, C, D and E) according to the final behavior score. Teachers can customize the educational content for each grade. 
The behavior grade is determined by the following A coefficient:

A = Learner_score * Number_of_active_learners / 100

The result indicates the grade according to the following table:

Table 1. Learner's behavior grade on Manhali system

\begin{tabular}{|c|c|}
\hline "A" coefficient & Grade \\
\hline Lower than 0.5 & E \\
\hline Between 0.5 and 1 & D \\
\hline Between 1 and 2 & C \\
\hline Between 2 and 4 & B \\
\hline Higher than 4 & A \\
\hline
\end{tabular}

\subsubsection{Behavior Study on a Platform Using}

\section{Manhali System}

This study conducted in May 2012, is addressed to first year students in computer science at ENS-Tetouan, Abdelmalek

Table 2. Calculate the total score by the seven indicators

\begin{tabular}{|c|c|c|c|c|c|c|c|c|c|c|}
\hline $\begin{array}{c}\text { Learner } \\
\text { Id }\end{array}$ & $\begin{array}{c}\text { Number of } \\
\text { connections }\end{array}$ & $\begin{array}{c}\text { Visited } \\
\text { pages }\end{array}$ & $\begin{array}{c}\text { Total } \\
\text { time } \\
\text { spent }\end{array}$ & $\begin{array}{c}\text { Tries in } \\
\text { self- } \\
\text { evaluation }\end{array}$ & $\begin{array}{c}\text { achieved } \\
\text { assignments }\end{array}$ & Messages & Comments & $\begin{array}{c}\text { Total } \\
\text { score }\end{array}$ & $\begin{array}{c}\text { "A" } \\
\text { coefficient }\end{array}$ & Grade \\
\hline 1 & $0.10549 \%$ & $\begin{array}{c}0.13619 \\
\%\end{array}$ & $0.0256 \%$ & $0 \%$ & $0 \%$ & $0 \%$ & $0 \%$ & $\begin{array}{c}0.03818 \\
\%\end{array}$ & 0.03398 & $\mathrm{E}$ \\
\hline 2 & $2.74262 \%$ & $\begin{array}{c}2.43446 \\
\%\end{array}$ & $\begin{array}{c}1.44412 \\
\%\end{array}$ & $2.73141 \%$ & $1.78571 \%$ & $2.75229 \%$ & $0 \%$ & $\begin{array}{c}1.98437 \\
\%\end{array}$ & 1.76608 & $\mathrm{C}$ \\
\hline 3 & $0.31646 \%$ & $\begin{array}{c}0.32346 \\
\%\end{array}$ & $\begin{array}{c}0.67304 \\
\%\end{array}$ & $0.75873 \%$ & $0 \%$ & $0.91743 \%$ & $2.22222 \%$ & $\begin{array}{c}0.74448 \\
\%\end{array}$ & 0.66258 & $\mathrm{D}$ \\
\hline 4 & $6.32911 \%$ & $\begin{array}{c}1.56622 \\
\%\end{array}$ & $\begin{array}{c}0.60197 \\
\%\end{array}$ & $1.28983 \%$ & $1.78571 \%$ & $1.72018 \%$ & $2.22222 \%$ & $\begin{array}{c}2.21646 \\
\%\end{array}$ & 1.97264 & $\mathrm{C}$ \\
\hline 5 & $4.11392 \%$ & $\begin{array}{c}2.75792 \\
\%\end{array}$ & $\begin{array}{c}5.12632 \\
\%\end{array}$ & $2.27618 \%$ & $1.78571 \%$ & $2.75229 \%$ & $0 \%$ & $\begin{array}{c}2.68748 \\
\%\end{array}$ & 2.39185 & $\mathrm{~B}$ \\
\hline
\end{tabular}

\subsection{Learning Style}

Manhali identifies the learning styles of learners with two different models, Felder's model and Kolb's model. Felder's learning styles are determined by the ILS questionnaire and Kolb's learning styles are automatically detected from the learners' behavior.
Essaadi University. We monitored the behavior of these learners for one month, the sample of the population was composed of 118 students, including 29 students have never accessed to the platform, 9 learners have accessed only one time and 80 learners have accessed more than once:

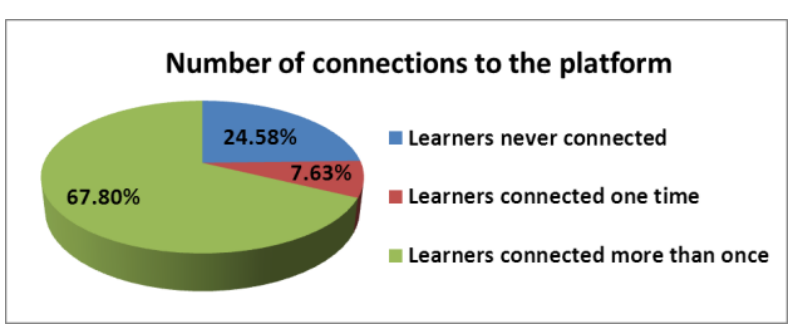

Figure 3. Statistics of learners' connections to Manhali platform

Manhali analyzes the learners' behavior to provide the behavior score and grade as follows:

\subsubsection{Felder's Learning Styles}

Manhali offers to learners the ILS questionnaire of Felder to determine their learning styles. The test results are instantly displayed to the learner with the degree of confidence; these results are also recorded in the learner profile. 


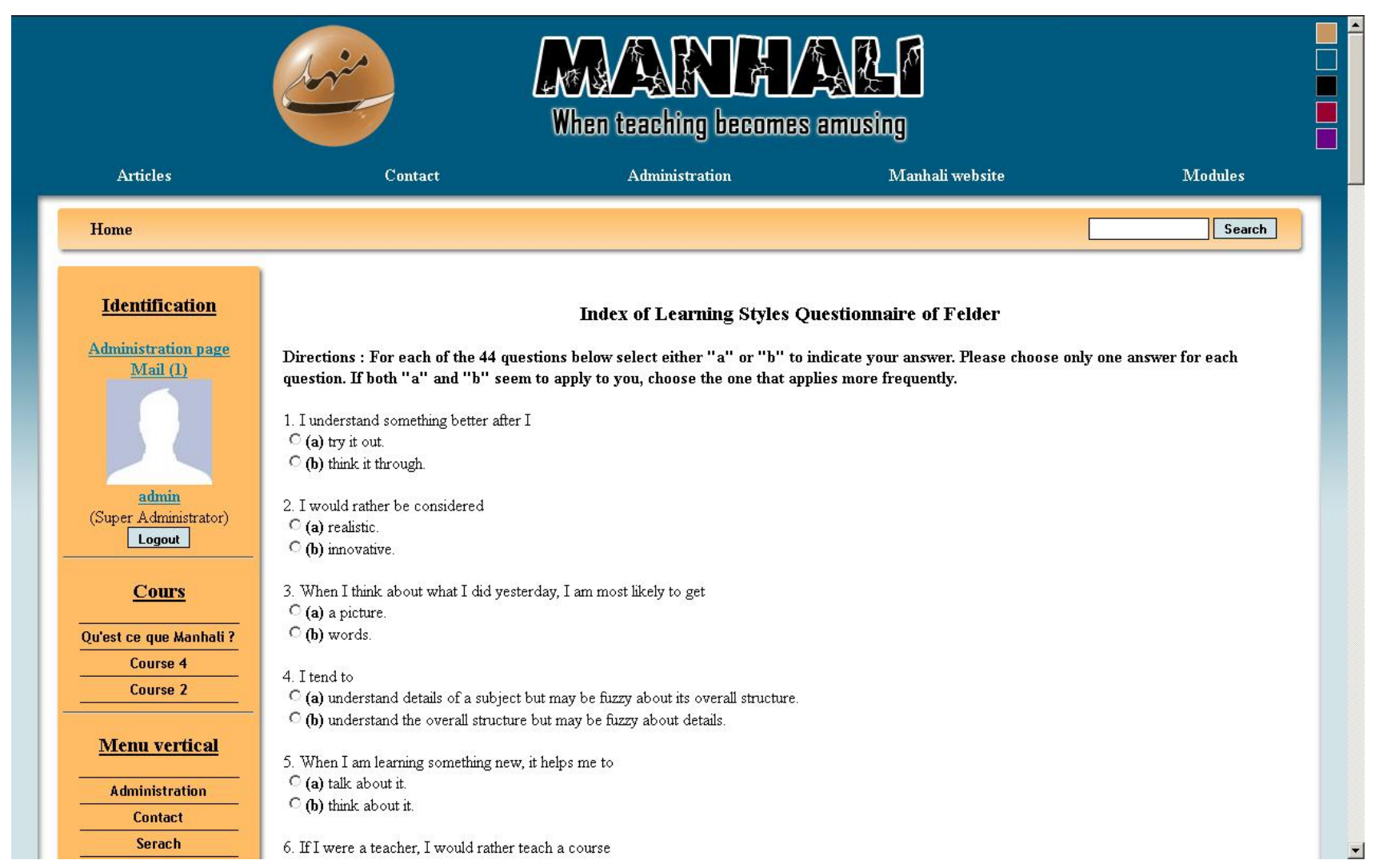

Figure 4. ILS questionnaire of Felder on Manhali system

\subsubsection{Kolb's Learning Styles}

The learning styles of kolb are determinated using indicators of behavior analysis that were mentioned before. We classified the four learning styles of Kolb on only two categories:

- The active experimentation (accommodating/converging style): This category includes students who prefer handling, task execution and activities implementation;

- The reflective observation (assimilating/diverging style): observers and conceptualizers who prefer to work on ideas and theories.

Each category is characterized by three indicators of our behavior analysis method. The active experimentation is characterized by the number of tries in self-evaluation tests, the number of achieved homework assignments and the number of comments. The reflective observation is characterized by the number of connections to the platform, the number of visited pages and the total time spent on the platform. The system calculates the "B" coefficient as follows:

$$
B=\frac{\sum \operatorname{Exp}_{\text {score }}}{\sum \operatorname{Obs}_{\text {score }}}
$$

Where:

- Exp_score is the total score of the three indicators of active experimentation: the number of tries in self-evaluation tests, the number of achieved homework assignments and the number of comments.

- Obs_score is the total score of the three indicators of reflective observation: the number of connections to the platform, the number of visited pages and the total time spent on the platform.

If $\mathrm{B}>1$, it means that the learner has the accommodating/converging style, otherwise the learner has the assimilating/diverging style.

For the 118 learners of our sample, we determined the learning style - according to the theory of Kolb - of 89 learners who have already accessed to the platform; however, the learning style still undefined for the rest:

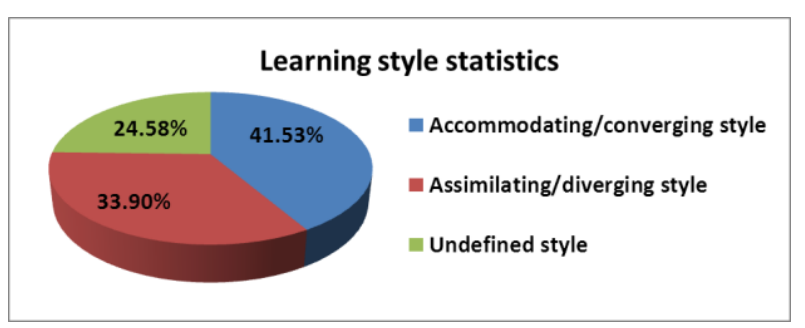

Figure 5. Kolb's learning styles on Manhali system

The learner profile therefore contains five components that we have detailed in this section: 


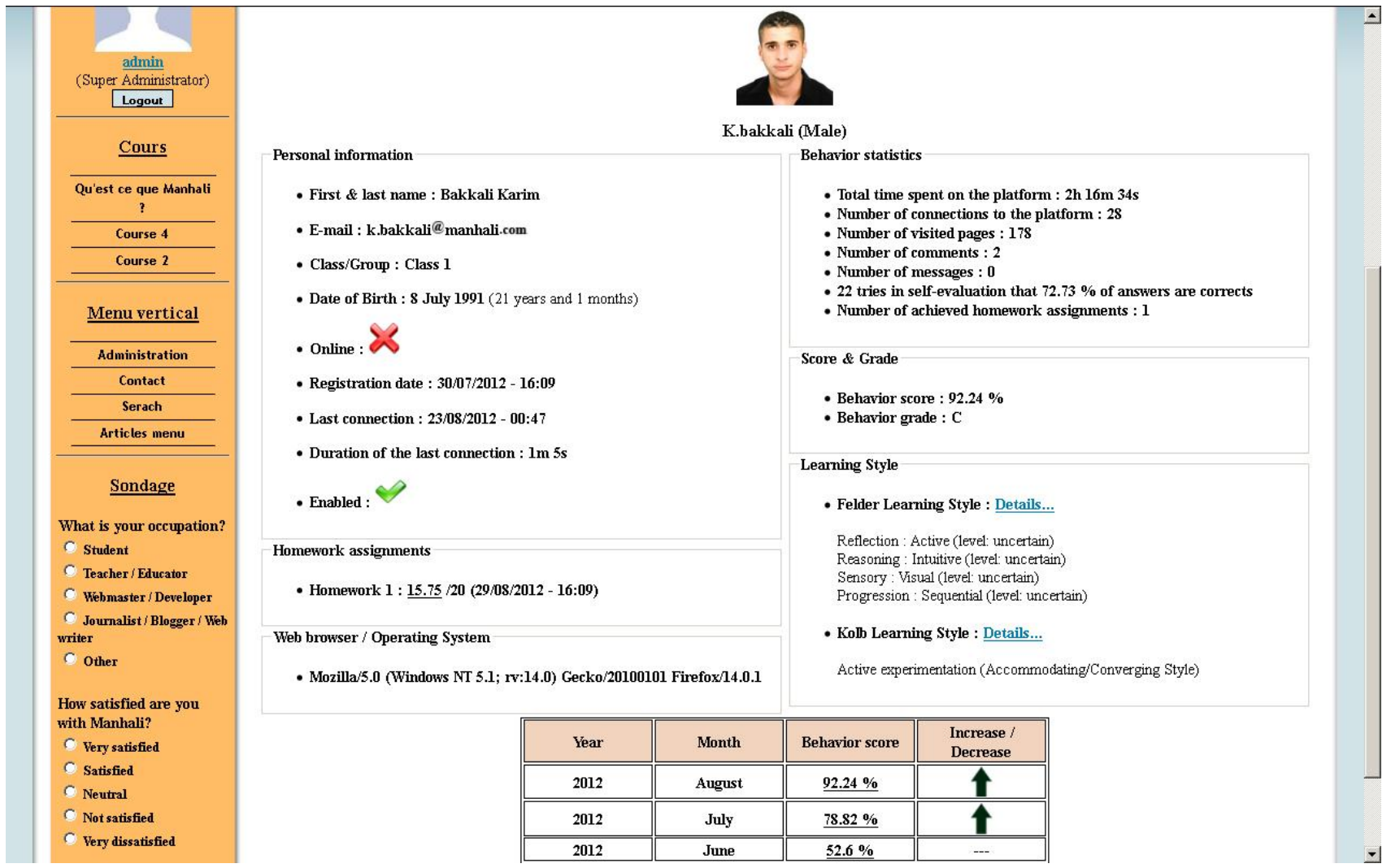

Figure 6. Learner profile on Manhali system

The system can also display the behavior score obtained by the learner for each month to allow teachers to compare the learner's behavior for a long time, this method can be useful to change learning strategies used for this learner if there is a remarkable decrement on his behavior for several months.

\section{CONCLUSIONS}

We have presented in this paper the learner profile created by Manhali, our learning management system that allows teacher to evaluate learners according to their online behavior, and to customize the learning by adapting the educational content to the current needs of each profile. The paper also shows our method to classify learners according to their behavior from observable indicators related to the pedagogical tools and to the learner interactions on the platform. These indicators allow us to create a new approach to detect learning styles based on the learners' behavior.

The data used in this paper are obtained from a study conducted among 118 first-year students in computer science in May 2012. This study has allowed us to follow the behavior of these learners for a month to test our new method that evaluates online behavior and measures learning style in real time.

\section{REFERENCES}

[1] EL HADDIOUI Ismail and KHALDI Mohamed (2012). "Learner Behavior Analysis on an Online Learning Platform". International Journal: Emerging Technologies in Learning (iJET), Volume 7, Issue 2, June 2012, pp. $22-25$.

[2] EL HADDIOUI Ismail and KHALDI Mohamed (2012). "Learner Behavior Analysis through Eye Tracking". International Journal of Computer Science Research and
Application (IJCSRA), Volume 2, Issue 2, April 2012, pp. 11-18.

[3] Sabine Graf, Taiyu Lin and Kinshuk (2005). "Improving student modeling: the relationship between learning styles and cognitive traits". IADIS International Conference on Cognition and Exploratory Learning in Digital Age (CELDA 2005), December 2005, Porto, Portugal, pp. 37-44.

[4] Popescu Elvira (2008). Thesis: "Dynamic adaptive hypermedia systems for e-learning". November 2008.

[5] J.J. Beshuizen and E.T. Stoutjesdijk (1999). "Study Strategies in a Computer Assisted Study Environment". Learning and Instruction, 9, pp. 281-301.

[6] J. Keefe (1979). "Learning Style: An Overview". NASSP's Student Learning Styles: Diagnosing and Prescribing Programs, pp. 1-17.

[7] R. J. Riding and S. Rayner (1998). "Cognitive Styles and Learning Strategies: Understanding Style Differences in Learning and Behaviour". David Fulton Publishers.

[8] W. James and D. Gardner (1995). "Learning Styles: Implications for Distance Learning". New Directions for Adult and Continuing Education, 67.

[9] A.F. Gregorc (1979). "Learning/Teaching Styles: Potent Forces behind Them". Educational Leadership, 36 (4).

[10] J. Keefe and B. Ferrell (1990). "Developing a Defensible Learning Style Paradigm". Educational Leadership, 48 (2).

[11] Piombo Christophe (2007). Thesis: "Modélisation probabiliste du style d'apprentissage et application à 
l'adaptation de contenus pédagogiques indexés par une ontologie". October 2007.

[12] Kolb David (1984). "Experiential Learning: experience as the source of learning and development". Englewood Cliffs, NJ: Prentice Hall.

[13] Felder Richard (1993). "Reaching the Second Tier: Learning and Teaching Styles in College Science Education". J. College Science Teaching, 23(5), 286-290. 1993.
[14] Felder Richard and Silverman Linda (1988). "Learning and Teaching Styles in Engineering Education". Engr. Education, 78(7), 674-681. 1988.

[15] Felder Richard and Soloman Barbara (2001). "Learning Styles and Strategies". Online at http://www4.ncsu.edu/unity/lockers/users/f/felder/public/ ILSdir/styles.htm

[16] Larry Cahill (2006). "Why sex matters for neuroscience". Nature Reviews Neuroscience, 2006. 